\title{
Perancangan Branding Sentra Kuliner PKL Wiyung Surabaya
}

\author{
Christyan Budi Susilo
}

Staff PengajarProgram Studi Desain Komunikasi Visual, Fakultas Seni, Institut Informatika Indonesia (IKADO) Surabaya

Email : christyan@iii.ac.id

Abstract - Sentra PKL Wiyung is a place where the culinary street vendors around Wiyung gathered together, where visitors can enjoy variety of available menu. In the absence of adequate design brand, not all people know about the existence of Sentra PKL Wiyung. The objective of redesigning Sentra PKL Wiyung's brand is to attract customers to the Sentra PKL Wiyung and be known in terms of design and comfort. The visual appearance is the important part for a brand. In terms of visuals, this rebranding design using manual techniques for sketching and using digital techniques for coloring. For the future, by doing this rebranding Sentra PKL Wiyung can have a good branding and promoting in more efficient way so that Sentra PKL Wiyung can be known by the people who live in Surabaya, especially by the people who live in Wiyung.

Keyword: Redesign, Brand.

\section{PENDAHULUAN}

Surabaya adalah ibukota dari provinsi Jawa Timur dan merupakan salah satu dari beberapa kota metropolitan di Indonesia. Sebagai sebuah kota metropolitan Surabaya memiliki berbagai macam daya tarik, salah satunya dalam bidang kuliner. di dalamnya terdapat berbagai macam kalangan dengan budaya yang beraneka ragam, maka kuliner di Surabaya juga sangat beragam. Sebut saja semanggi, kupang lontong, nasi bebek, rawon setan, penyetan, rujak cingur, tahu tek, tahu campur, dan lain-lain. Akibatnya banyak sekali restoran, warung, depot, pujasera, foodcourt yang terdapat di kota Surabaya. Ada G-Walk, The Loop, Surabaya Town Square, Food Festival yang memiliki pangsa pasar kalangan menengah ke atas. Di Surabaya juga terdapat berbagai macam warung, depot, rumah makan, pujasera, dan Sentra PKL (Pedagang Kaki Lima).Sentra PKL adalah sebuah tempat yang dibangun sebagai wadah para PKL untuk berjualan. Sebelum diwadahi, para PKL berjualan di tepi- tepi jalan, hal ini sering menyebabkan kemacetan, membuat kotor jalan, yang berakibat terjadinya penggusuran PKL oleh SATPOL PP. Dengan adanya Sentra PKL ini, diharapkan para PKL tersebut dapat berjualan tanpa harus khawatir oleh penggusuran yang dilakukan SATPOL PP. Yang akan kami bahas dalam penelitian kami adalah Sentra 
PKL yang berlokasi di Wiyung.

Sentra PKL Wiyung didirikan oleh paguyuban yang terdiri dari para PKL di Wiyung. Sentra PKL Wiyung memiliki 21 stand makanan yang berjualan secara bergantian dalam 2 shift, dari jam 5 pagi 5 sore dan jam 5 sore - jam 12 malam. Sentra PKL Wiyung memiliki pangsa pasar kalangan menengah ke bawah dan selama ini Sentra PKL Wiyung tidak pernah melakukan promosi. Berdasarkan hasil survey dan analisa yang telah kami lakukan terhadap pemilik, penjual, dan konsumen dari Sentra PKL Wiyung, kami mendapatkan beberapa permasalahan yang tengah dihadapi oleh Sentra PKL Wiyung, yaitu:Permasalahan lahan parkir, Masalah perluasan lahan, Masalah kepengurusan Sentra PKL Wiyung, Masalah logo/brandname yang susah diingat, Masalah promosi Sentra PKL Wiyung / komunikasi marketing/tidak adanya signboard, Sentra PKL Wiyung kurang dikenal. Untuk mewujudkan hasil branding yang baik, brand sentra PKL wiyung memerlukan beberapa aspek meliputi :

- Brand awareness, Kemampuan calon pembeli untuk mengenali dan mengingat kembali bahwa suatu merek merupakan bagian dari suatu kategori produk.

- brand perceived quality, Persepsi konsumen mengenai kualitas yang dimiliki suatu merek dalam produk yang dilabelinya.

- brand association, Segala kesan yang muncul dalam benak seseorang yang terkait dengan ingatannya mengenai suatu merek (Aaker, 2000)

- brand loyalty. Tingkat kesetian konsumen terhadap sebuah merek. Menjadi ukuran seberapa besar kemungkinan pelanggan akan berpindah ke merek lain.

Kemudian dilakukan langkah - langkah sebagai berikut :Brand Research \& Analyst, Brand alignment, Brand identity, dan Brand Management.

\section{METODE PENELITIAN}

Jenis data yang didapatkan diperoleh dari berbagaisumber secara absah yang dapat mendukung untuk proseredesain. Pencarian data dilakukan melalui metode sebagai berikut:

- Mengidentifikasi Fenomena dan Problematika

- Studi eksisting dan studi kompetitor serta komparator

- Hasil wawancara pengurus Sentra dan para penjual makanan di dalam sentra.

- Studi Literatur dan teori yang berhubungan

- Hasil dari polling dan kuesioner untuk mengetahuikeinginan audiens serta menemukan permasalahan.

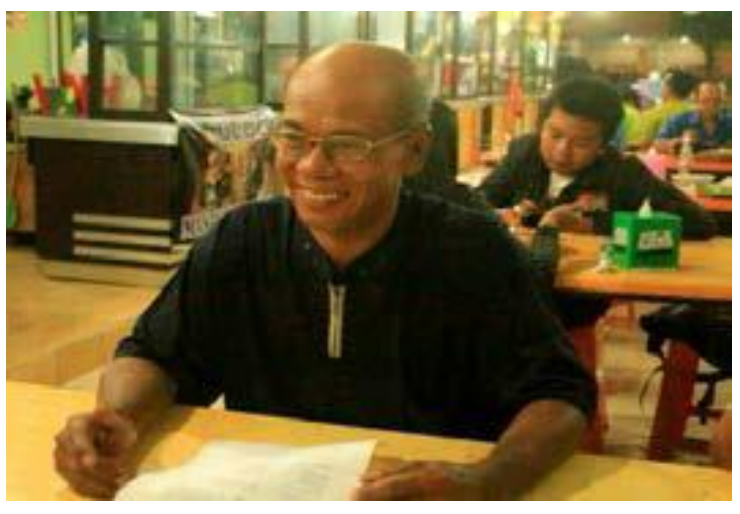

Gambar. 1. Proses wawancara terhadap pengurus sentra

Penelitian yang dilakukan dengan perencanaan terlebih dahulu berisi tahapan 
proses penelitian sebelum nantinya akan memasuki tahapan perancangan. Adanya proses asistensi dan presentasi antara peneliti dan rekan pihak lain sangat diperlukan untuk menampung saran dan masukan yang membangun dan sebagai evaluasi dalam proses penelitian dan perancangan. Tahapan penelitian dan perancangan yang direncakanan dapat digambarkan dengan skema di bawah ini :

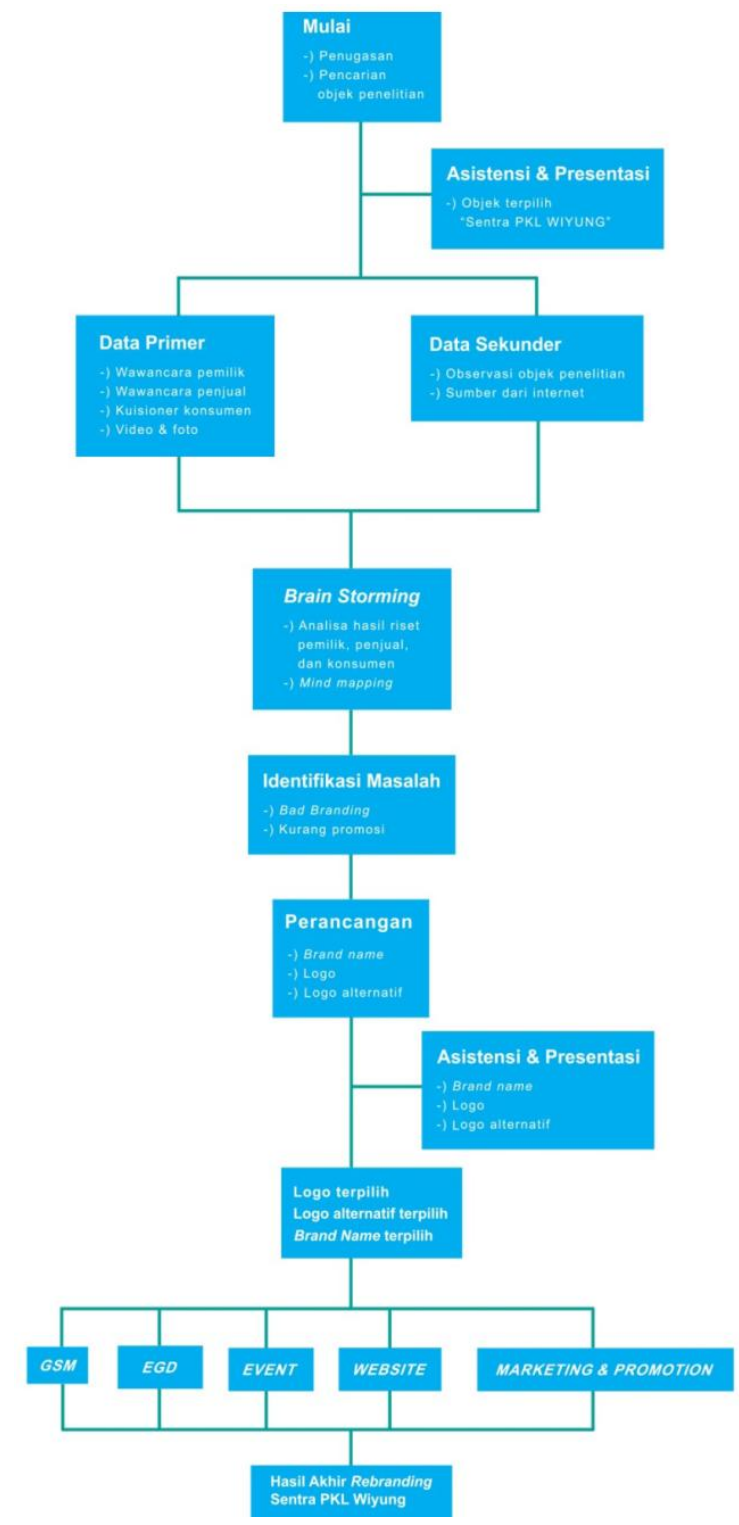

Gambar.3. Skema Teknik Perancangan yang diterapkan dalam proses penelitian dan perancangan tentang sentra PKL Wiyung Surabaya

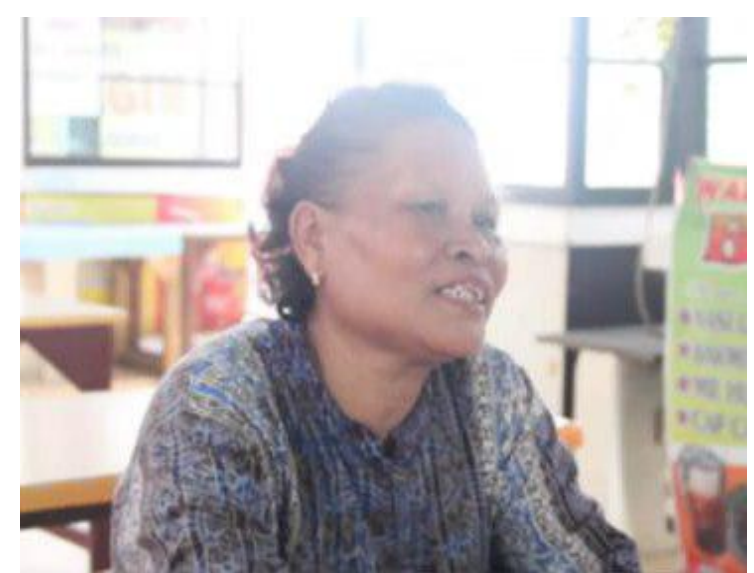

PROSES DESAINGambar. 2. Proses wawancara terhadap para penjual

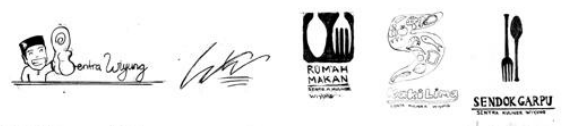

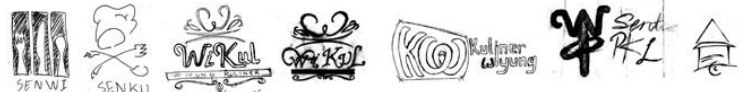

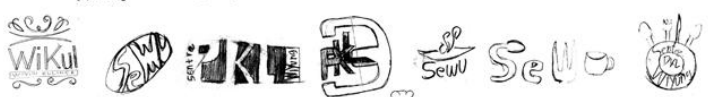

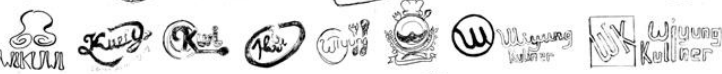

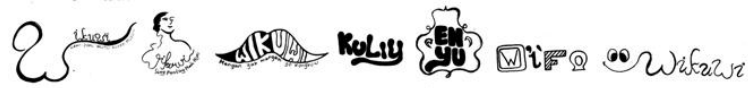
음

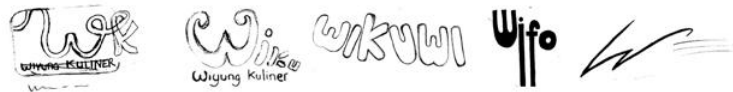
Seang sek

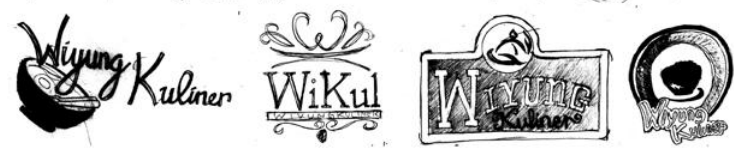

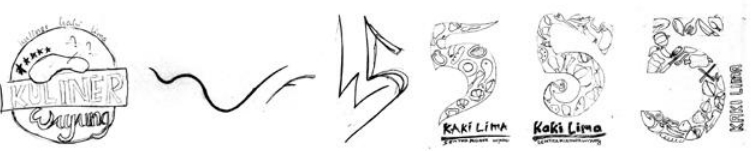

Gambar.4. Proses alternative sketsa desain.Tahap 1(atas) dan tahap 2 (bawah).

Proses perancangan logo yang akan digunakan dalam rebranding Sentra PKL Wiyung diawali dengan pencarian nama baru yang lebih menjual untuk Sentra PKL Wiyung. Setelah menemukan beberapa nama baru, maka proses perancangan logo pun memasuki tahap paling awal, yaitu 
tahap pembuatan sketsa logo. Pada tahap ini kami membuat beberapa sketsa logo dari Sentra PKL Wiyung dengan cara manual, setelah sketsa logo yang terkumpul cukup banyak maka proses perancangan logo pun memasuki tahap yang kedua. Pada proses perancangan logo untuk Sentra PKL Wiyung tahap kedua ini kami mengumpulkan semua sketsa logo yang telah kami buat, kemudian kami melakukan proses penyeleksian logo dari sejumlah sketsa logo yang telah terkumpul. Proses penyeleksian ini dilakukan untuk mendapatkan logo yang memiliki visualisasi yang baik, sesuai dengan konsep, serta dirasa mampu untuk mewakili citra baru dari Sentra PKL Wiyung yang kami buat. Setelah melalui proses penyeleksian maka kami pun berhasil memilih beberapa sketsa logo dari banyak sketsa logo yang telah kamibuat. Setelah beberapa logo dan alternatifnya terpilih maka proses perancangan logo untuk Sentra PKL Wiyung pun memasuki tahap yang ketiga yaitu tahap digitalisasi.

Pada proses perancangan logo untuk Sentra PKL Wiyung tahap yang ketiga, yaitu tahap digitalisasi, kami melakukan pembuatan versi digital dari sketsa logo yang telah terpilih pada tahap kedua.

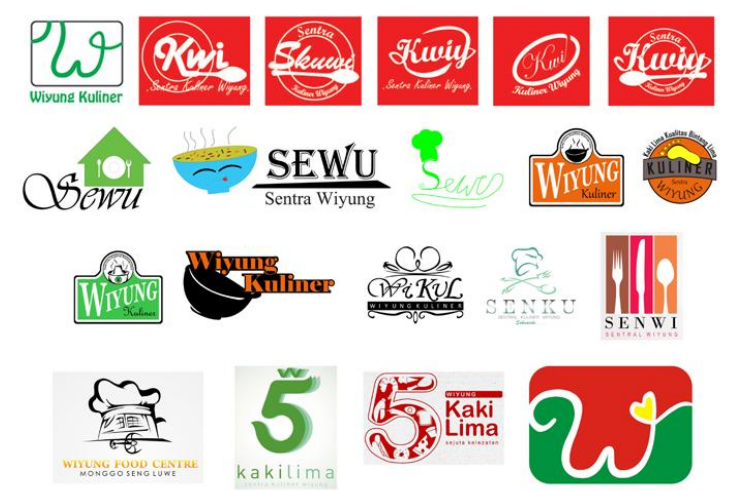

Gambar.5. Proses desain tahap 3 dan 4. Bagian kanan ujung bawah adalah desain terpilih.
Pada proses digitalisasi ini dilakukan vektorisasi logo, pewarnaan, dan juga pembuatan alternatif dari logo-logo yang telah lolos dari seleksi pada tahap kedua.Pada tahap keempat dari proses perancangan logo untuk Sentra PKL Wiyung ini, sketsa logo yang telah melalui proses digitalisasi pada tahap ketiga sehingga berubah menjadi format vector graphic kami presentasikan. Presentasi ini bertujuan untuk menjelaskan konsep dari logo - logo tersebut. Setelah logo - logo itu selesai kami presentasikan maka dilakukan penyeleksian untuk memilih sebuah logo yang akan menjadi logo baru bagi Sentra PKL Wiyung dan logo yang terpilih tersebut akan digunakan dalam proses rebranding dari Sentra PKL Wiyung. Berdasarkan hasil dari penyeleksian yang telah dilakukan maka terpilihlah logo dan nama Wiyung Kuliner sebagai logo dan nama baru bagi Sentra PKL Wiyung.

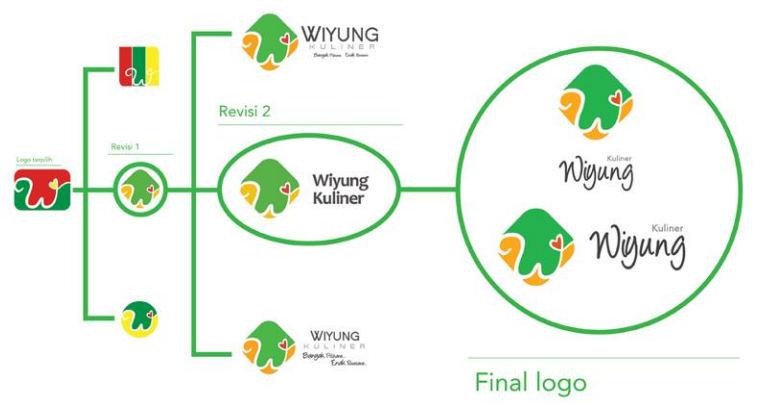

Gambar.6. Desain final yang melalui berbagai tahapan revisi desain.

Pada proses perancangan logo bagi Sentra PKL Wiyung tahap terakhir ini, kami melakukan berbagai revisi pada logo Wiyung Kuliner yang telah terpilih untuk memberikan solusi atas berbagai kekurangan dari logo Wiyung Kuliner 


\section{DESAIN FINAL}

Setelah melalui berbagai proses perancangan, presentasi, dan revisi maka desain final untuk rebranding dari Sentra Kuliner Wiyung pun terpilih. Adapun desain final untuk rebranding dari Sentra Kuliner Wiyung terdiri dari beberapa bagian yaitu Logo dan supergrafis, Stationery, Merchandise, Marketing dan promosi, Environmental Graphic Design, Event dan Website.
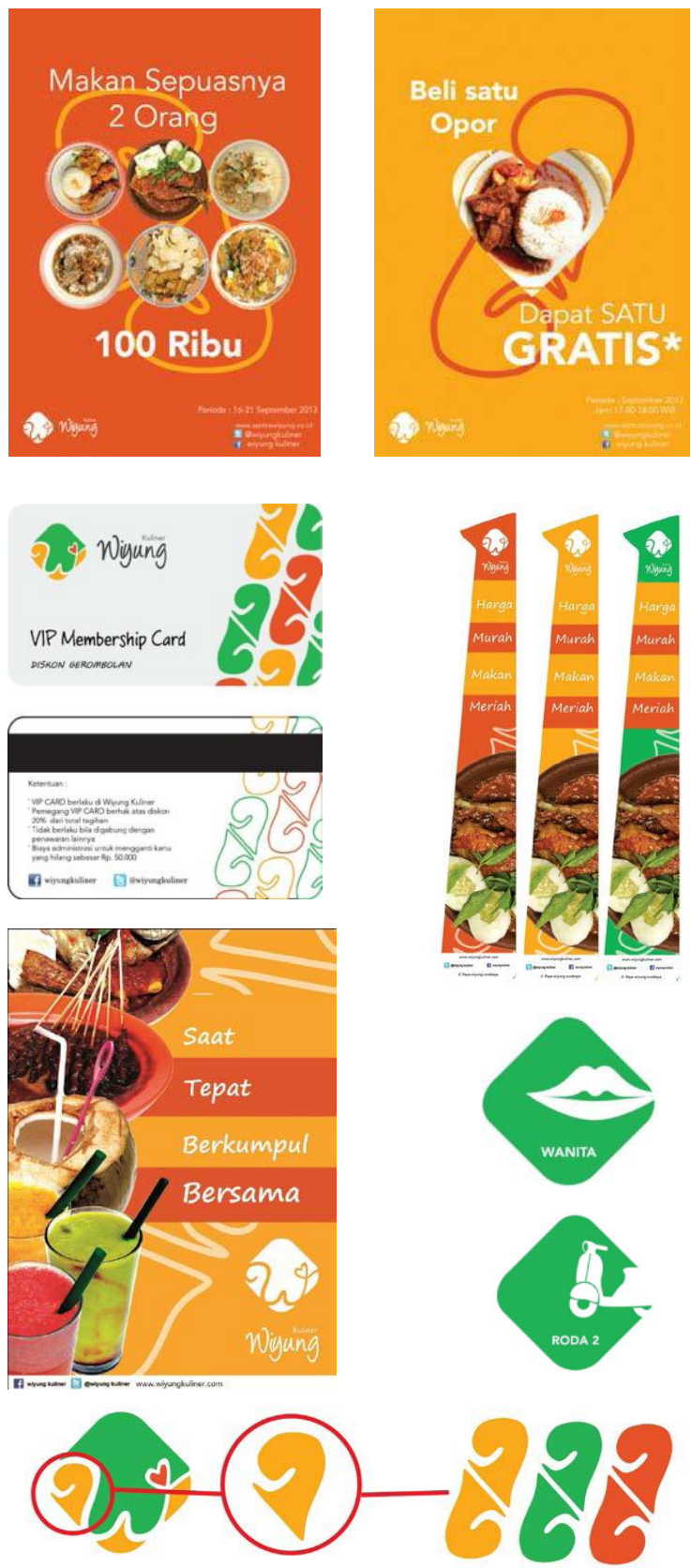
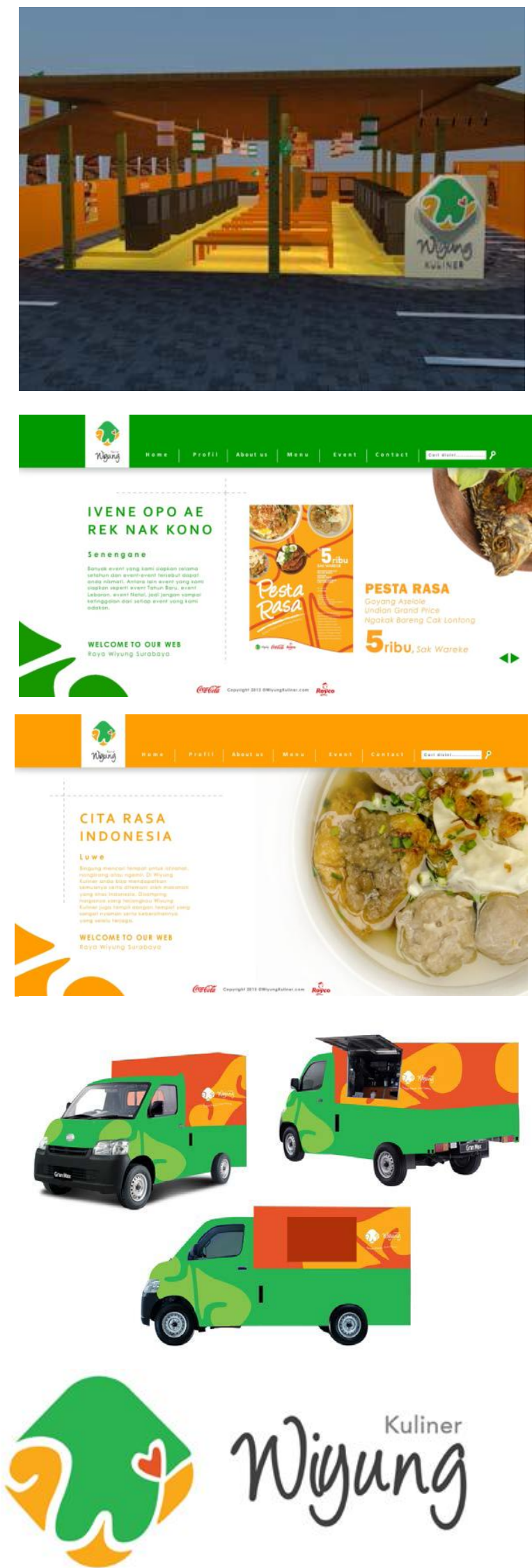

Gambar.7. Desain Final meliputi berbagai media. 
Selain itu branding terhadap sentra PKL Wiyung juga meliputi rencana ke depan yaitu event seperti acara pembukaan dan acara untuk menyambut bulan puasa atau Ramadhan serta acara menyambut tahun baru. Perancangan ini bertujuan agar sentra PKL Wiyung dapat mengikuti apa yang terjadi di sekitar dan nantinya pengunjung tidak jenuh dan tetap ramai dikunjungi.
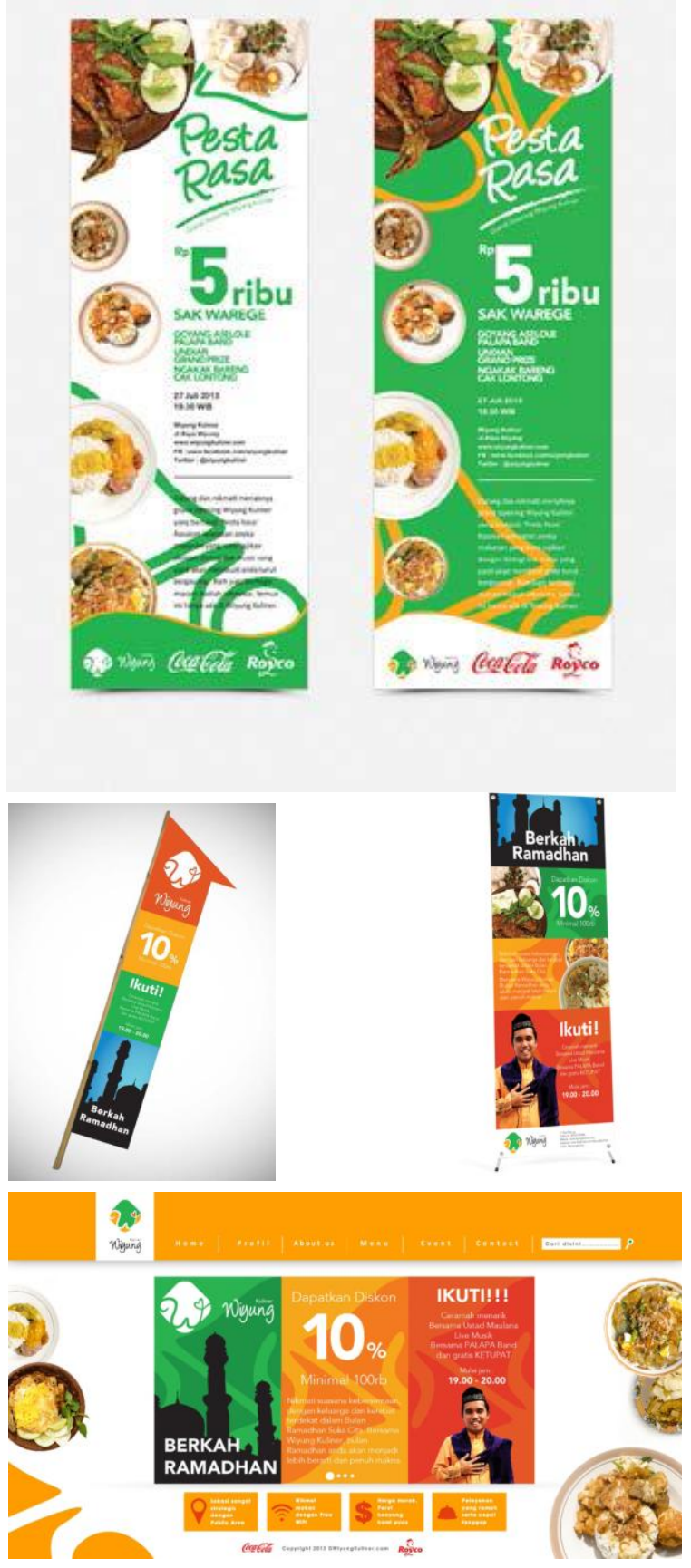
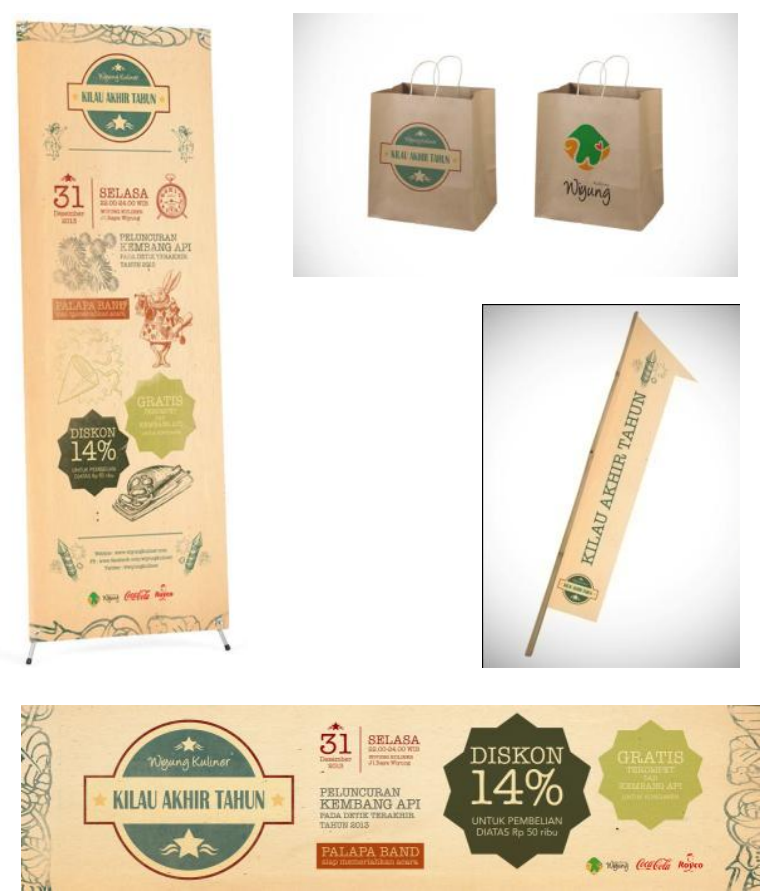

Gambar.8. Desain Final untuk acara pembukaan, tahun baru dan bulan Ramadhan

\section{KESIMPULAN}

Dalam perancangan rebranding untuk Sentra PKL Wiyung ini dapat diambil kesimpulan bahwa dalam membuka usaha, branding yang baik sangat penting karena branding merupakan upaya untuk membentuk citra yang postif di mata konsumen dan masyrakat, sehingga branding secara langsung mempengaruhi ketertarikan konsumen terhadap produk yang ditawarkan. Selain itu branding yang baik juga membuat konsumen mudah mengenali dan mengingat brand yang dimiliki, serta meningkatkan rasa ingin tahu dan daya beli konsumen. 


\section{DAFTAR PUSTAKA}

1. Wibowo, Tri. 2002. Teori warna untuk desainer. $\mathrm{T}$ desain!Hidup berkualitas tak sekedar kuantitas, (online), (www.triwibowo.com/teori-warna-untukdesainer-2, diakses 10 Juli 2013).

2. Selame, Elinor. 1988. The company image. Jakarta: John Wiley and Sons Inc.

3. Kasali, Rhenald. 1994. Manajemen public relations konsep dan aplikasinya. Jakarta : Pustaka Utama Grafiti.

4. Gregory,James R. 1999. Marketing corporate image.Jakarta :McGraw Hill Professional.

5. Anggoro, M. Linggar. 2005. Teori dan profesi kehumasan serta aplikasinya. Jakarta : Bumi Aksara.

6. Sutojo, Siswanto. 2004. Membangun citra perusahaan. Jakarta : Damar Mulia Pustaka.

7. Rustan, Srianto. 1999. Mendesain logo. Jakarta : PT Gramedia Pustaka Utama.

8. Yustitia. 2013. Manisnya yogya manisnya gudeg wijilan. Wisata Kuliner, (online). (www.kuliner.panduanwisata.com, diakses 10 juli 2013).

9. Wheeler, Alina. 2009. Designing brand identity.Jakarta :John Wiley and Sons Inc.

10. Landa,Robin. 2006. Designing brand experiences. Jakarta : Cengage Learning. 